\title{
Student Success Impacts in Communication and Professional Networking Contexts
}

\author{
Alyson Eggleston \\ The Citadel \\ Robert J. Rabb \\ The Citadel
}

\begin{abstract}
Student-driven success in professional networking contexts is qualitatively surveyed and assessed in an engineering-specific technical writing and communications (TWC) course required at an undergraduate institution. This TWC course was designed in part to provide pre-internship preparation for engineering students. Data captured from several semesters indicates a positive trend of industry partners' selection of TWC students for internships and employment. This data is corroborated by student-led surveying of peers who identify important connections between TWC course content and professional application. This paper identifies the range of TWC content that can be refined and leveraged during networking events.
\end{abstract}

Keywords: internships, professionalization, technical communication

\section{INTRODUCTION}

Engineering students show strong preferences for experiential learning opportunities, like internships, but need enhanced communication skills to ensure successful professional growth and experience. Successful professional experiences and preparation are supported by the continuing development of engineering students' communication abilities, a view supported by the National Academy of Engineers $(2004,2005)$ and the most recent vision statements of the American Society of Mechanical Engineers (2012), the American Society of Civil Engineers (2009), as well as ABET (2020).

To sustain student engagement, education literature advises educators to create active learning experiences, while avoiding student indifference (Davis, 1993; Raelin, 2007; Ambrose, et al., 2010). Many students have difficulty understanding classroom theory with ambiguous examples and terms and prefer active learning experiences. Engineering students across academic institution types show strong preferences for experiential learning, a finding that several studies have reproduced (Felder \& Silverman, 1988; Felder \& Spurlin, 1995).

Internships, then, represent a unique setting wherein engineering students can engage in active learning and increase their motivation and commitment to the discipline. The American Association of Colleges and Universities states that internships are among a collection of educational best practices (high impact) that improve outcomes for students pursuing degrees across both liberal arts and professional disciplines (Kuh, 2008). Internships have also been found to be important for professional preparation (Verney, et al., 2009) and encouraging retention in the engineering discipline (Safiz, et al., 2011; ASEE, 2012; Backnak, et al., 
2013). Internships also provide students with real world opportunities for personal and professional development through mentor shadowing, attendance at meetings, briefings, and actual performance of duties.

While many schools do not require internship experience as a prerequisite for graduation, internships offer real-world application of communicative strategies acquired through course work. Internships serve to reinforce the skills needed to meaningfully interact with a professional community. Internships support students in developing learning strategies and problem-solving skills while partnered with Subject Matter Experts (SMEs) whose roles as scientists and engineers serve to guide students in their work on innovative technology. At The Citadel, internship relationships can persist, culminating in employment opportunities after graduation. Engineering students are encouraged to find an internship, and faculty have several industry contacts who seek faculty assistance to employ an intern. These relationships often result in companies committing to working with, developing, and then hiring the students once they graduate. Students report anxiety due to not knowing all the answers, which is typical for an ungraduated engineering student who is still developing fundamental and technical skills. However, after developing increased communicative competence, an engineering intern can interact with an organization productively and make measurable impacts. Student interns gain confidence through learning the right answers, while also addressing other disciplinary knowledge gaps. Meanwhile, organizations challenge student interns to ask why and if there is a better approach.

Engineering students deserve to be well prepared for the formative and summative opportunities of internships, which result from the beneficial interaction of professionalism, communication, and technical skills (Safiz, et al., 2011). However, many students are unable to see the supporting alignment between their developing communication abilities and their engineering curriculum. At The Citadel, writing and verbal briefings are typically assessed in General Education courses that are outside of students' interest areas, and this requirement continues to evolve (Eggleston \& Rabb, 2018). To bridge the gap between developing communication skills and technical content, engineering students and certain science and math majors must now take a TWC course as part of the general education curriculum. Development of this TWC course was principally motivated by the needs of the School of Engineering with regard to industry expectations and professional development (Itani \& Srour, 2015), and the course contents include written, verbal, and visual forms of communication as well as professional preparation, and its course projects have been well described in other studies (Eggleston \& Rabb, 2018; Eggleston \& Rabb 2019a).

Using student- and faculty-derived data and reports, this paper expands upon a previous student-run survey that sought to better understand engineering curriculum impacts on internship experiences (Floyd, et al., 2017). The current study represents an effort to measure TWC-to-career impacts as well as existing student skill gaps. Student perspectives and reported experience are presented as motivators for curricular improvements, ensuring the TWC course at The Citadel remains relevant while adapting to students' evolving requirements and opportunities.

\section{BACKGROUND AND INSTITUTIONAL SETTING}

Although many senior level engineering students at The Citadel participate in internships for academic credit, many do not wait until their senior year for this experience. Many will seek an engineering internship, typically over the summer, primarily for the pay. As a rising sophomore or junior, they have limited technical knowledge to contribute. However, as a rising sophomore through senior, they can improve their team-based problem-solving ability and learn a suite of new communicative and technical skills through internship experiences. Perhaps learning from both theory and example is one of the greatest benefits of an internship, not only for technical subjects, but also for professional skills. The TWC course, required for all engineering students at The Citadel may seem like another theory course to some of the students, but many have found success obtaining an internship and maintaining positive internship interactions by applying the material from the TWC course (Eggleston \& Rabb, 2019a). 
Responding to previous best practices research that establishes communication and professionalism as key to maintaining great intern-employer relations, the authors developed the following research questions (Eggleston \& Rabb, 2019b):

1. Did students observe growth in their communication and professional skills after having taken the TWC course?

2. Did non-technical information from the academic environment resonate with the students during the internship?

3. How well do the TWC course objectives position students for success after graduation?

All engineering students at The Citadel must take a TWC course, typically during the sophomore year. The course uses a variety of assignments and projects that exercise basic tenets of technical writing and communications to include: audience, purpose, brevity, clarity, simplicity, etc. Students are assessed on writing, speaking, and visual communication requirements. As part of the grade, the students must accomplish a number of tasks and assignments that directly and indirectly contribute to their ability to earn an interview, capture an internship, and ensure a successful professionalization experience. These tasks include elevator pitches and resume design, as well as professional writing tasks: executive summaries; instructional writing; white papers; memoranda; and email.

Each semester at The Citadel, there is a Career Fair, and each fall there is an engineering-specific Career Fair and networking exposition. Many students seek the assistance of the institution's Career Center to prepare their resumes, interview, and negotiate. Although the Career Center is a great resource, they are often overwhelmed before a Career Fair, and many students cannot get the assistance when they wait too long. Many engineering students at the institution anecdotally report attending these half-heartedly as part of a class assignment to talk to employers. The TWC course specifically prepares engineering students to initiate interactions and sustain them with recruiters, while developing a professional portfolio that prepares them to converse about their preparation and skillsets with recruiters. In this way, the TWC course functions as a formal support for engineering students, in addition to the ancillary support available to all Citadel students through the Career Center. Typically, a majority of students are surprised by their ability to hold a conversation with a stranger, and may receive a follow-up interview for an internship or job for the effort.

\section{METHODS}

Assessment of the TWC course's impact was partially motivated by student perception of the value of knowledge and skills gained in the course and its influence in acquiring and performing well during internship interviews, and progress through the interview process, possibly resulting in internship capture. Data in this study was expanded (Floyd, et al. 2017) and collected through a survey administered to many of the seniors, juniors and sophomores who had completed an internship $(n=23)$ and current students aided in survey recruitment. The IRB-approved survey discussed in this paper was administered after students completed the TWC course and had time to reflect on the content of the course. Data was captured both online and through paper copy responses to the survey, depending on student availability and convenience. The questions essentially gaged the students' perception of their professional skills after the course.

Using a standard five-level Likert scale in which a response of "1" indicated "strongly disagree" and a "5," "strongly agree," the survey asked participants to indicate to what degree they agreed with a survey statement. Using a Likert scale delivered increased granularity in student responses more than a yes or no, true or false format would. The 5-level Likert scale also allowed for a greater span in response types, indicating degree of agreement or disagreement. Additionally, students at The Citadel are accustomed to surveys with Likert-based responses as part of their ongoing leadership development.

\section{DATA}

\section{Surveys}

Survey categories were developed from previous internship maintenance studies, focusing on written, verbal, and visual communication; real world application of engineering concepts; and professionalism 
(Rabb, et al., 2009; Safiz, et al., 2011; Floyd, et al, 2017; True, 2018). The first category of the survey asked the students to rate their professional skills or traits after they completed the course. The students were rating on the basis of whether they had either further developed or practiced the skills from course experiences relevant to their internship experience. The first category consisted of ten skills or traits which included the following.

1. Communication - writing

2. Communication - speaking

3. Communication - visual presentation

4. Work Quality - attention to detail and improved work standards

5. Self-assessment of own strengths and weaknesses regarding professional communication skills

6. Organization

7. Time Management

8. Teamwork and group leadership

9. Personal appearance and conduct standards

10. Confidence

The first five can be objectively correlated through assignments in the course (Eggleston \& Rabb, 2018; Eggleston \& Rabb 2019a), while the last five are self-reported on personal growth. Results from this survey can be seen in Figure 1, which generally shows positive results in all areas.

FIGURE 1

\section{PERSONAL / PROFESSIONAL SKILLS}

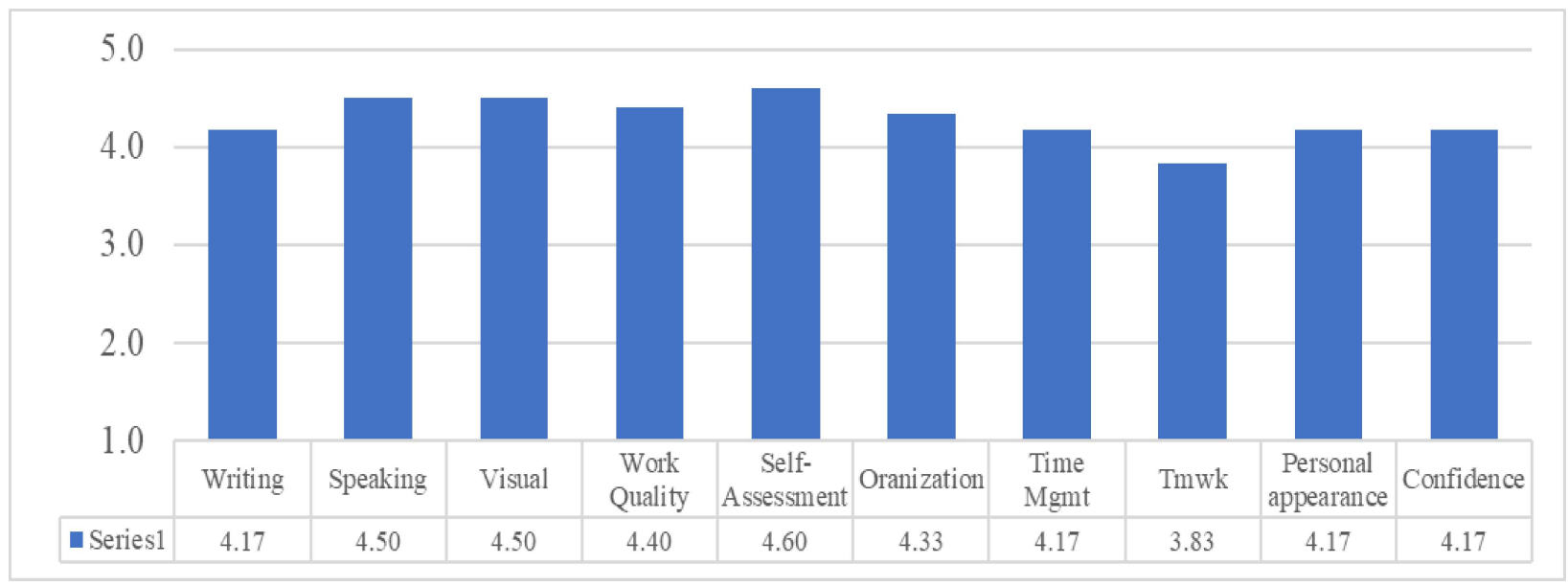

Figures 2-4 show the distribution and standard deviations of the ten professional skill measures above. Where the number of survey respondents vary, it indicates an individual did not provide a response for that item. Time Management and Teamwork (Figure 3) both show a high degree of variation. As these are developmental skills subject to continual refinement throughout the arc of the career, it is not unexpected that students report a range of positive and negative self-perceptions in these areas. 
FIGURE 2

DISTRIBUTION OF WRITING, SPEAKING, VISUAL, WORK QUALITY SELF-PERCEPTIONS
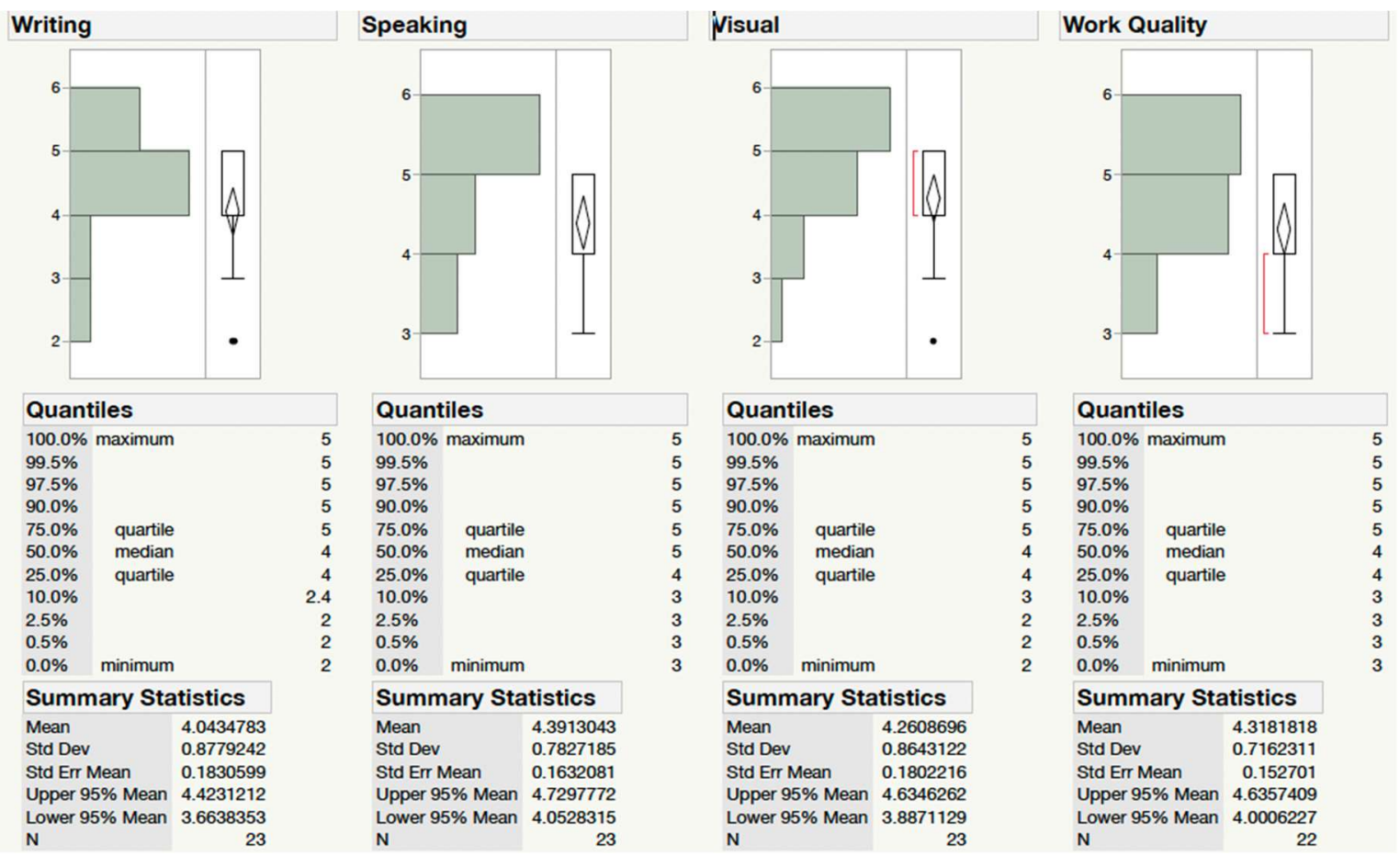

FIGURE 3

DISTRIBUTION OF SELF-ASSESSMENT, ORGANIZATION, TIME MANAGEMENT, AND TEAMWORK SELF-PERCEPTIONS
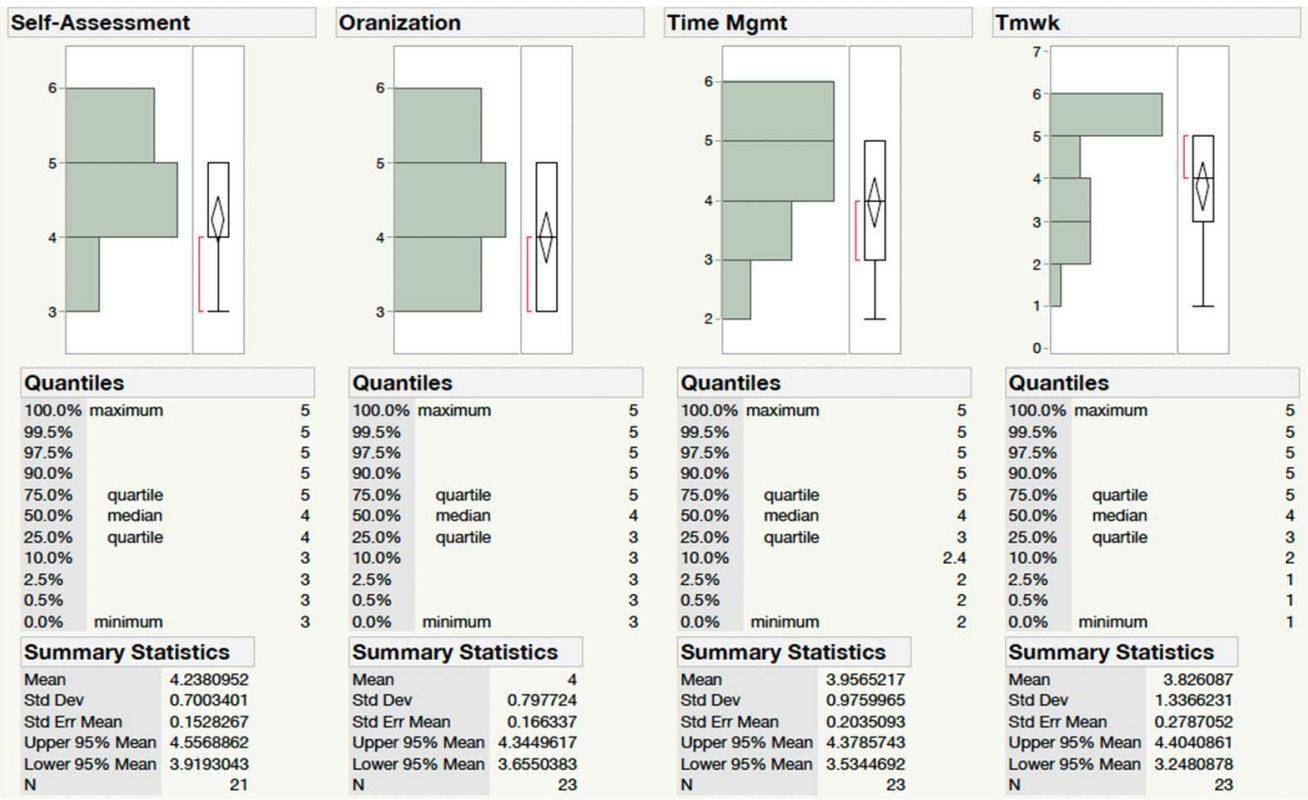
FIGURE 4

DISTRIBUTION OF PERSONAL APPEARANCE AND CONFIDENCE SELF-PERCEPTIONS

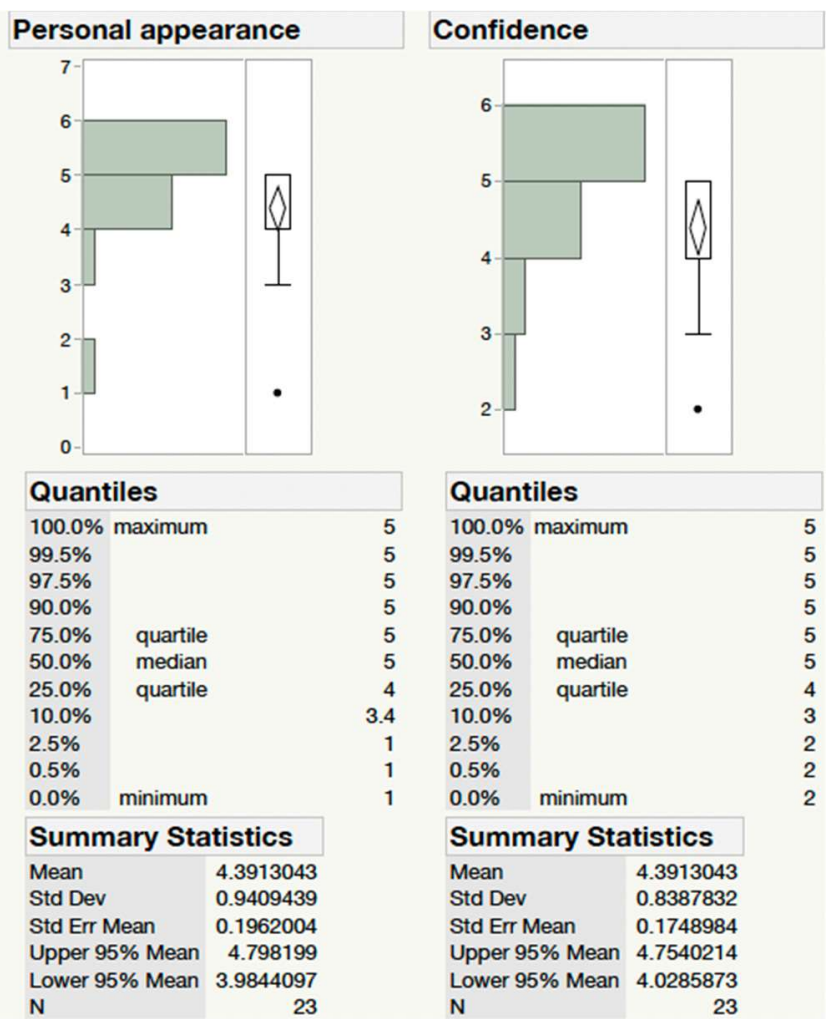

Next, the survey assessed the student's perception of the connection that their TWC course had with their internship work. Only students who already had an internship experience (before or after the TWC course) responded to this second category, and so there are fewer $(\mathrm{N}=20)$. Some questions assessed the opinion of the students for how often they were able to relate topics between the TWC course and their internship. The other questions measured more generally the level of benefit that their TWC course provided to their internship experience. These six statements (Floyd, et al., 2017) are as follows, and a graph of the self-perception results is provided in Figure 5. Again, there was a general positive agreement that the TWC content benefited them as an intern.

1. I have applied prior knowledge learned from my studies to a concept or problem that I have experienced during interning.

2. I have applied prior knowledge learned from interning to a concept or problem that I have experienced during my studies.

3. I am often able to relate academic content to my work while interning.

4. Interning has provided me with an interest, excitement, and motivation for my academic studies.

5. My internship experience has helped me in deciding a possible career path.

6. I believe an engineering related internship is a valuable opportunity. 
FIGURE 5

TWC COURSE RELEVANCE TO INTERNSHIP

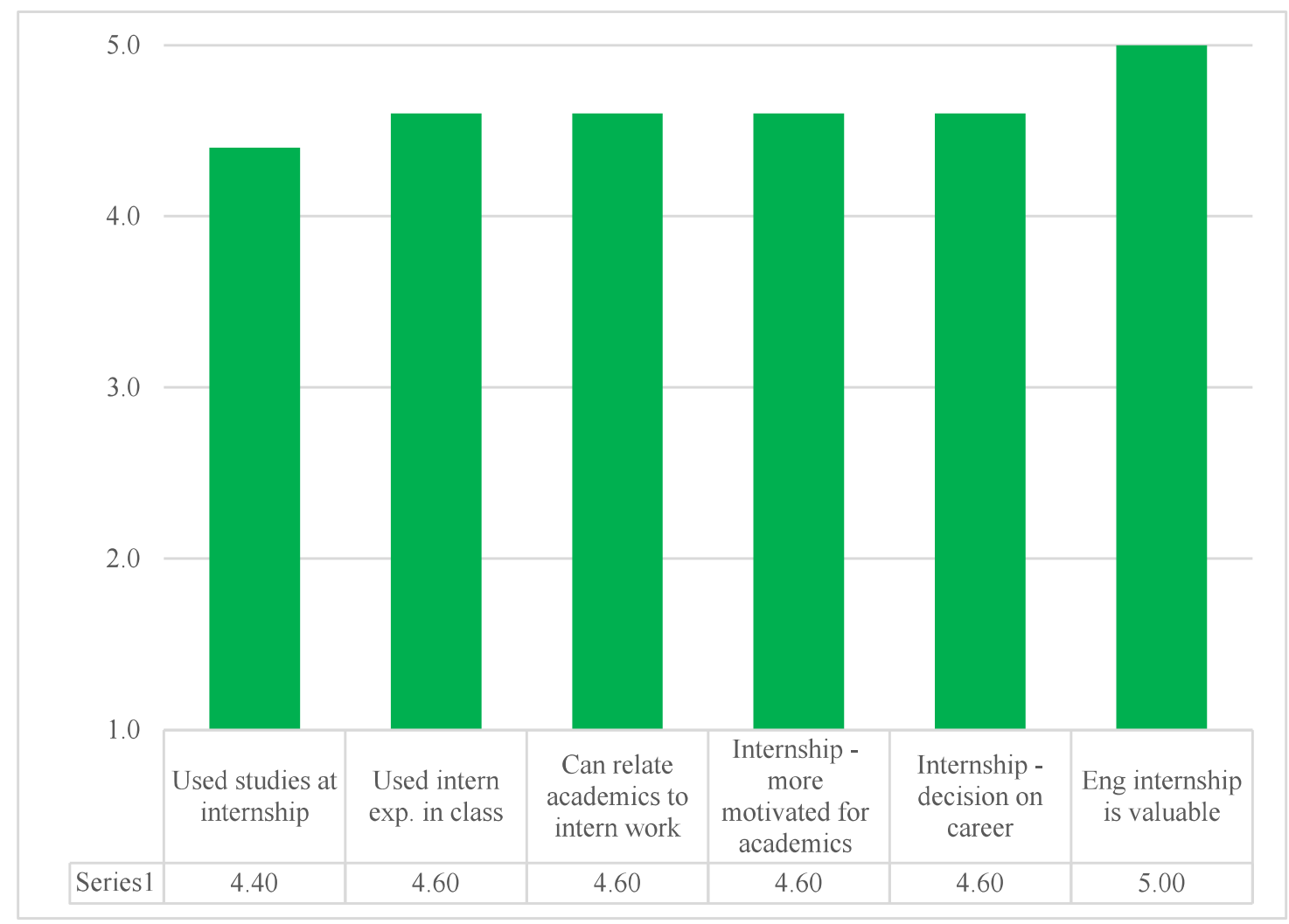

As an ad hoc analysis, the authors sought to find any correlative indicators of the self-perceptions of both Figure 1 and Figure 5, representing the TWC-specific skills in the former and evidence of internshipapplication in the latter. An r-value matrix of correlative values indicates that all else being equal, scores on Confidence are highly positively correlated with scoring on Speaking $(r=0.7255)$ and Personal Appearance $(\mathrm{r}=0.7762)$. Similarly, there exists a strong positive correlation between scoring on Teamwork and Time Management $(\mathrm{r}=0.7953)$. Table 1 summarizes these selected correlations. Strong negative correlational values were not observed in the data. While this analysis is only exploratory, $r$ values above 0.5 merit interest and potential further study.

TABLE 1

SELECTED R-VALUE MATRIX OF SELF-PERCEPTIONS

\begin{tabular}{|l|l|l|l|}
\hline & \multicolumn{1}{|c|}{ Speaking } & \multicolumn{1}{c|}{ Personal Appearance } & \multicolumn{1}{c|}{ Time Management } \\
\hline Confidence & 0.7255 & 0.7762 & -- \\
\hline Teamwork & -- & -- & 0.7953 \\
\hline
\end{tabular}

\section{Semester-end Student Feedback}

In a separate survey of internship on-boarding experiences, students taking the TWC course during Spring 2019 and Fall 2019 semesters signal strong internship capture and industry interaction rates among sophomore-level engineering students. In Figure 6, 58\% of students had either been offered an internship or were engaged in the interviewing process $(n=64)$. Career Services at The Citadel has acknowledged that this is significantly higher than their placement rates for engineering students as a whole. Similarly, Fall 2019 (Figure 7) shows 49\% of students have either captured an internship or are involved in the 
interviewing process $(n=50)$. While this measure is lower than the previous semester, the hiring cycle data for internships consistently dips in Fall and rebounds in Spring, when hiring budgets have been approved in the industries specific to the region. As more internship capture data is collected during Spring 2020, it is expected that these numbers will meet or exceed those of 2019.

\section{FIGURE 6}

\section{COMM 260 INTERNSHIP CAPTURE RATES AT SPRING 2019 SEMESTER END}

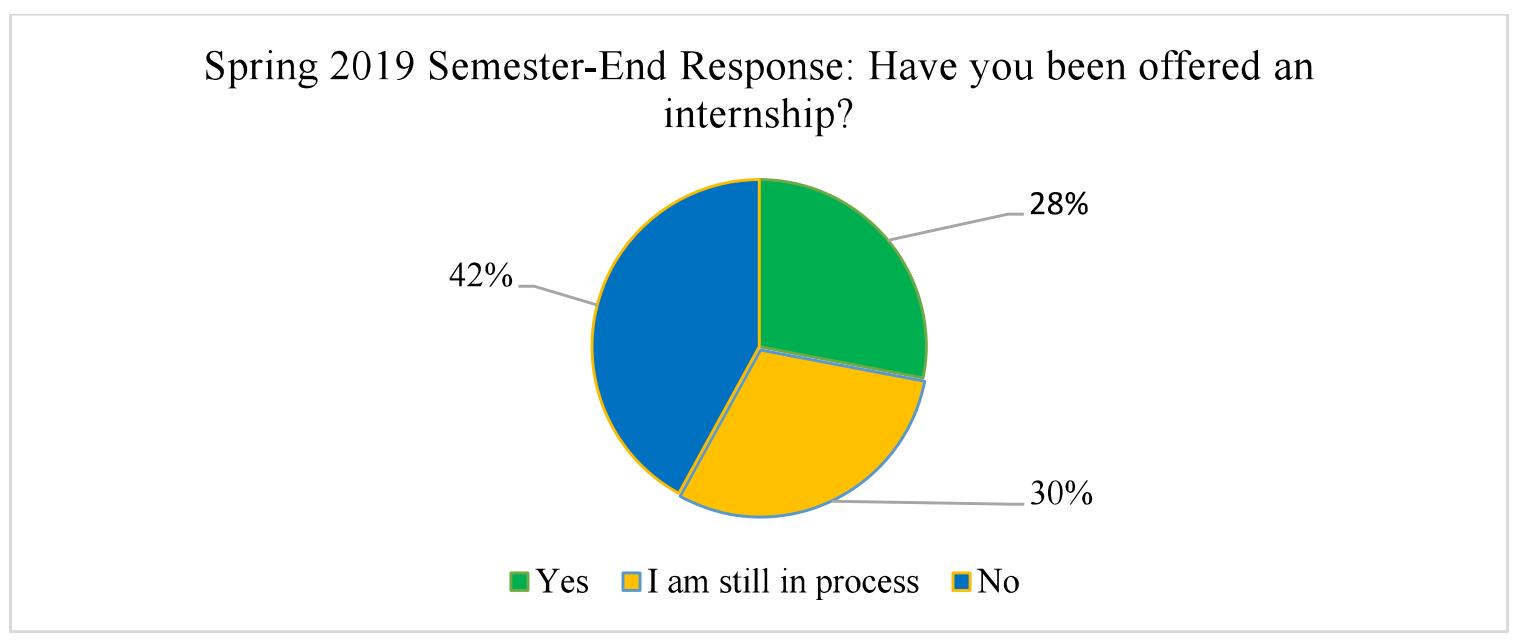

FIGURE 7

COMM 260 INTERNSHIP CAPTURE RATES AT SPRING 2019 SEMESTER END

Fall 2019 Semester-End Response: have you been offered an internship?

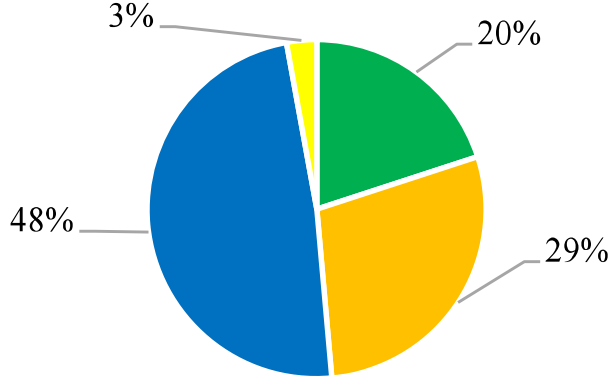

- Yes $\quad$ I am still in process $\quad$ No $\quad$ Other

Sophomore-level TWC students are able to readily map in-class professional writing projects to their successful experiences at recruitment events. In a Spring 2019 semester-end survey, students were asked: What about this class has been useful for you in terms of pre-professional training? In response, students highlighted the increased development of their professional skills, communication, and confidence. The following are two excerpts:

1. "It has helped me build a stronger resume and allowed me to create my first elevator pitch, which helped me out tremendously when talking to recruiters. Thanks to the resume and elevator pitch I have secured an internship this upcoming summer with [redacted]." (Spring 2019) 
2. "This class has allowed me to work on and improve my social skills as well as, point out some discrepancies and other items I need to work on in order to make myself a better candidate." (Spring 2019)

In response to the same survey question provided in a Fall 2019 semester-end survey, students consistently noted the change in attitude, behavior, communication style they were beginning to adopt as a result of the class. The following are excerpts from that survey.

1. "This class exposed me to the professional mindset or way of thinking and how to use this mindset to be successful in the future." (Fall 2019)

2. "[This class has been most useful in] getting me ready to fit right into the workforce already sounding and acting professional, as if I have had years of experience." (Fall 2019)

3. "This class has opened my eyes to the civilian sector of professionalism. After attending the career fair, I realized the importance of clear verbal communication, and precise physical communication. I really enjoyed the opportunity to experience something that was not so military driven." (Fall 2019)

\section{DISCUSSION}

Engineering students who participated in internships comprehend the importance of professional skills, such as teamwork, time management, and communication. Surveys concurrent with the TWC course and post-TWC reflect these results. Also important is the fact that students recognized that a one-semester course in technical writing and communications would not be enough for mastery or future professional opportunities. Instead, they realized they must engage in continuous improvement and become self-learners.

Both positive and negative feedback are central to the continuous improvement of course offerings. Negative feedback can show opportunities for improvement. However, positive feedback identifies content areas that are value-added, positioning students to develop and thrive beyond the classroom. Additionally, positive feedback show areas to sustain in course content. This study shows that Teamwork and Time Management continue to be areas with greater range in student discernment of mastery, and indicate an opportunity to develop. These professional skills represent areas to engage students more deliberately throughout the curriculum. While finding time in the curriculum to develop these skills deliberately may be a challenge, however, this study shows a student-perceived skill disparity.

Professional skill categories on the survey were all rated highly (above 4.0), except Teamwork. Student respondents were mainly sophomores or above who have had multiple opportunities to work together with other students in their majors, and had already developed teamwork skills. The TWC course had several small team projects, but none that tested interpersonal skills. Some professional skills ranked markedly lower than others. However, the skills that rated low were not rated low due to any underdevelopment of the skill but rather were not seen as matching the standards at The Citadel, which has a very strict dress and conduct code. Time management was the next lowest score, and this is indicative of the standards of the school, which ensures that students are occupied with academic activities during the day, athletics or fitness usually in the afternoon, and mandatory study time.

From the data, the skills that rated high are those that internship employers expect. The most notable of the highly rated skills was students' self-assessment ability. Students also were able to interact with their internship organizations while developing speaking, visual presentation, and writing skills. Although the writing skill was lower, it reflects the fact that many students went to technical internships and did not exercise this skill. Students also were able to develop or practice verbal communication skills which allow them to gain professional confidence, an important impact that results the students becoming well-rounded individuals and engineers upon graduation. The internship experience functions overall as a means for selfreflection-each student evaluates his or her own strengths and weaknesses, positioning them for continuous individualized professional development before they graduate and join the work force.

After reviewing the results of the second set of questions on the student survey, relating TWC coursework to internship work, their perception of the overall value of the internship stands out most significantly. All other questions showed very positive agreement that the content and skills from the TWC 
were applied and developed at the internship, and that they were able to return to classroom with enhanced communication skills and knowledge. Given these results and context, students are clearly linking and applying their TWC course materials with their necessity in the engineering field.

The comparatively high scores of questions 4 and 5 indicate that students are attributing educational value to their internship experiences. As students see a direct application of TWC content with their they are also motivated to engage more deliberately with their coursework. Furthermore, students are comprehending a better awareness of engineering professional skills and expectations, which contributes to their matriculation in an engineering career. This self-knowledge ideally allows students to more accurately select a career path in which they will be positioned for success.

Practically speaking, while internships reinforce classroom content in a novel context, they also help students gain confidence in their career choices. Acknowledging increasing tuition costs, students need reassurance that their degree programs will result in their being fully marketable upon graduation and leaving the support of the institution. Internships offer a means by which colleges can support student career goals, while developing professional skills. Internship experiences also provide a valuable feedback tool for supporting and improving college curricula that should be responsive to meet industry demands (Coco, 2000).

\section{CONCLUSION AND FUTURE WORK}

Incorporating more time for technical writing and communications education is difficult with a full curriculum, but indirectly, the internships offer some solution to reinforce the communication skills. There are many variables that affect the success of students' internship experiences, including student competence and motivation, the institution's internship program, and the sponsoring organization's leadership. When a student can put into practice professional communication skills to earn an internship and hone those skill during the internship, the students and the engineering profession win. Quantitative results suggest that TWC skills are important and directly applicable, requiring very little reinforcement with discipline-specific courses. This study provides a baseline of data and information to continue developing the TWC course and content. The TWC skills are a link between classroom theory and concepts and real time impacts.

One takeaway for improvement is priming students in their curriculum better before they participate in their internship experiences. Correlative results suggest that confidence-building and continued team-based exercises may be key to improving student performance and self-perceptions. Any changes to improve communication skills must be assessed and reinforced in the engineering curriculum. The TWC curriculum has shown numerous benefits, and continued, and even expanded, college support is vital. More organizations have expressed interest in partnering with the institution each year. This trend is expected to grow. Maintaining and encouraging these industry partnerships will be continuous work and function as an investment in the students.

\section{ACKNOWLEDGEMENT}

(C)2020 American Society for Engineering Education. ASEE Annual Conference Proceedings, June 2020, Virtual Conference

\section{REFERENCES}

ABET. (n.d.). [Online]. Retrieved May 1, 2020, from http://www.abet.org.

Ambrose, S., Bridges, M., DiPietro, M., Lovett, M., \& Norman, M. (2010). How Learning Works: 7

Research-Based Principles for Smart Teaching. John Wiley \& Sons.

American Society of Civil Engineers. (2009). Achieving the Vision for Civil Engineering in 2025. Reston, VA: ASCE. 
American Society of Mechanical Engineers. (2012). ASME Vision 2030: Creating the Future of Mechanical Engineering Education, Executive Summary, ASME Board on Education. [Online]. Retrieved April 29, 2020, from go.asme.org/v2030

ASEE. (2012, August). Going the Distance: Best Practices and Strategies for Retaining Engineering, Engineering Technology and Computing Students. ASEE Retention Project. [Online]. Retrieved Aril 29, 2020, from https://www.asee.org/retention-project

Bachnak, R., Goonatilake, R., Maldonado, S.C., \& Mott, D. (2013, June). Promoting student success in engineering and science through research and internship programs. Proceedings of 2013 ASEE Annual Conference \& Exposition. Atlanta, GA. [Online]. Retrieved April 29, 2020, from https://peer.asee.org/22386

Coco, M. (2000). Internships: A try before you buy arrangement. S.A.M. Advanced Management Journal, 65(2), $41-47$.

Davis, B. (1993). Tools for Teaching. San Francisco, CA: Jossey-Bass Publishers.

Eggleston, A.G., \& Rabb, R.J. (2019a, June). Experiential learning and communication: iFixit in the technical writing classroom. Proceedings of 2019 ASEE Annual Conference \& Exposition. Tampa, FL. [Online]. Retrieved May 1, 2020, from https://peer.asee.org/32793

Eggleston, A.G., \& Rabb, R.J. (2018, June). Technical communication for engineers: Improving professional and technical skills. Proceedings of 2018 ASEE Annual Conference \& Exposition. Salt Lake City, UT. [Online]. Retrieved April 30, 2020, from https://peer.asee.org/31068

Eggleston, A.G., \& Rabb, R.J. (2019b, June). Returning to an industry-informed technical writing and communication course design. Proceedings of 2019 ASEE Annual Conference \& Exposition, Tampa, FL. [Online]. Retrieved May 1, 2020, from https://peer.asee.org/33246

Felder, R.M., \& Silverman, L. (1988). Learning and teaching styles in engineering education. Eng. Educ., $78(7), 674-681$.

Felder, R.M., \& Spurlin, J. (2005). Applications, reliability and validity of the index of learning styles. Int. J. Eng. Educ., 2l(1), 103-112.

Floyd, C., Johnson, K., \& Rabb, R. (2017). Engineering internships-Individual and program assessment. In Proceedings of the 2017 ASEE Zone II Annual Conference (pp. 2-5).

Itani, M., \& Srour, I. (2015). Engineering students' perceptions of soft skills, industry expectations, and career aspirations. Journal of Professional Issues and Engineering Education Practice, 142(1). [Online]. Retrieved May 1, 2020, from http://dx.doi.org/10.1061/(ASCE)EI.1943-5541.0000247

Kuh, G. (2008). High impact educational practices: What they are, who has access to them, and why they matter. Association of American Colleges and Universities, 14(3), 28-29.

National Academy of Engineering (NAE). (2004). The Engineer of 2020: Visions of engineering in the new century. Washington, DC: National Academies Press.

National Academy of Engineering (NAE). (2005). Educating the Engineer of 2020: Adapting engineering education to the new century. Washington, DC: National Academies Press.

Rabb, R., Nowicki, M., \& Bristow, E. (2009, June). Engineering internships for first year engineering and undeclared majors. Proceedings of 2009 ASEE Annual Conference \& Exposition. Austin, Texas. [Online]. Retrieved April 30, 2020, from https://peer.asee.org/4781

Raelin, J. (2007). Toward an epistemology of practice. Academy of Management Learning \& Education, 6(4), 495-519.

Saviz, C.M., Fernandez, A.A., Basha, E.A., Ellis, A.P., Hammarstrom, K., Leon, F., . . Ton, S. (2011, June). Engineering internships in social entrepreneurship: Developing partnerships and student perspectives. Proceedings of 2011 ASEE Annual Conference \& Exposition. Vancouver, BC. [Online]. Retrieved April 29, 2020, from https://peer.asee.org/17877

True, M. (2018). Starting and maintaining a quality internship program ( $9^{\text {th }}$ edition). intrueition.com [Online]. Retrieved August 23, 2020, from http://www.intrueition.com/uploads/4/8/ 0/7/4807298/starting an internship program-9th edition-revised.pdf

Verney, T., Holoviak, S., \& Winter, A. (2009). Enhancing the reliability of internship evaluations. The Journal of Applied Business and Economics, 9(1), 22-34. 